\title{
A Study on the Illustration Translation of Chinese Painting Composition Rules
}

\author{
HUI Juan, JIA Xiaoqing \\ University of Shanghai for Science and Technology, Shanghai, China
}

\begin{abstract}
The Chinese painting composition rules are depending on practical and aesthetic nature. At present, the translation research on Chinese painting texts is few. In order to make cross-cultural understanding faster and better, the cultural connotation behind it is the basic problem that needs to be solved. This paper attempts to use the illustration-based means — original picture editing, simple drawing, and GIF (Graphics Interchange Format) as visual representations to help translate the semantic information of the Chinese painting composition rules, in order to meet the needs of modern reading, and consolidate the effect of Chinese culture "going out".
\end{abstract}

Keywords: Chinese painting composition, rules, translation, illustration

\section{Introduction}

The basic theory of Chinese painting composition from conception to pattern is not only the product of the development of Chinese painting itself, but also an organic combination of philosophical literature, poetry, books, and paintings, and a highly unified content and form. It is the perfect embodiment of realism and romanticism ( $\mathrm{Lu}, 2008$, p. 10). The original name of composition in traditional Chinese painting is "Zhāngfã (章法)” or “Bùjú (布局)”. And Chinese painting composition has certain normative requirements (Guo, 2010, p. 70). This paper takes the illustration-based representations of Chinese painting composition as the starting point, which is combined with the significance test method (T-test) to calculate whether the difference between the two sets of data is obvious and try to use the corresponding Chinese painting pictures or images as external visual interpretation to enable Chinese paintings to be understood easily by westerners, and increase the possibility of applying Chinese paintings in other fields.

\section{The Connotation of Chinese Painting Composition Rules}

Many painters from the past and the present have attached great importance to the form and factors of composition: one of the "Six Cannons" of the South Qi Dynasty critic Xie He "operating position"; Pan Tianshou, a famous painter in the 20th century said: "xū (empty) without shí (solid) is not easy to be itself, shí (solid) without xū (empty) cannot be itself too. There will not be shū (scattering) without mì (gathering), vice versa. When xū (empty) interacting with shí (solid) and shū (scattering) interacting with mì (gathering),

Acknowledgement: Thanks to the grant of 2018 key project of humanities and social sciences of USST (No. SK18ZD06) and the grant of high-level university construction of USST (No. 10-18-113-007).

HUI Juan, master's degree, Institute of Foreign Languages, University of Shanghai for Science and Technology, Shanghai, China.

JIA Xiaoqing, Ph.D., associate professor, Institute of Foreign Languages, University of Shanghai for Science and Technology, Shanghai, China. 
drawing a Chinese painting matters".

"Yin and Yang is the Geat Way"-The Book of Changes explained a simple dialectic in ancient China, which covers the universal law of everything in the universe, and the traditional concept of composition of Chinese painting is in line with it (Mogaboo, 2016, p. 57). According to the fifth-century scholar Yan Yanzhi, there are three kinds of diagrammatic signs: first, the magical hexagrams in The Book of Changes, representing "nature's pinciples" (Tú lî); second, the ideograph, or written word, "concepts" representing (Tú shì); and finally, painting, representing "nature's form" (Tú Xíng). Wen C. Fong, a professor of Chinese art history at Princeton University, interprets the three maps as "a work of art is perceived as a physical mark of the artist, as well as a diagram, or metaphor, of the dynamic but harmonious balance of the universe" (Wen, 1992, p. 4).

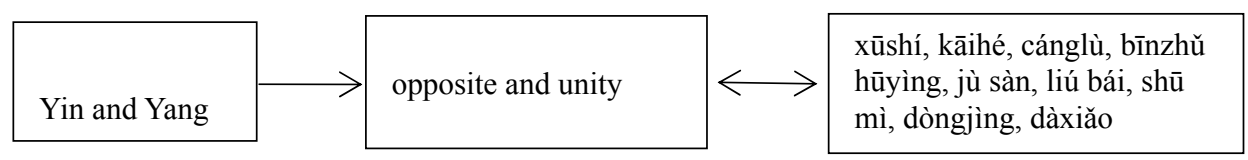

Figure 1. Principles of Chinese painting composition under the concept of naturalness: opposite and unity.

\section{The Translation Strategies of Chinese Painting Composition Rules}

Operating instructions. We selected and downloaded four clear Chinese painting pictures from the Palace Museum and the Shanghai Museum official website ready to be used. The reason why online selection rather than online shopping replicates ancient paintings one by one was because modern people are more exposed to information by electronic products, and there are time and space restrictions in accessing paper brochures or visiting museums. The tested population was divided into a teenage group (15-18 year old junior high school students) and an adult group (21-29 year old college students or working people). The two groups were divided into A and B, each with 15 persons, and there were a total of 60 people. Group A test process: The testee sat in the designated position to read the definition of the three terms of the Chinese painting composition rule in three minutes through Powerpoint content, and then went out to fill out the questionnaire; Group B test process: The testee sat in the designated position to read composition rule terms definitions with related Chinese painting pictures, and then went out to fill out the questionnaire. Of course, there are inevitably two doubts - What is the relationship between the Chinese as the testee and the audience overseas? Is it a delusional question? What are the reasons for sampling the age of the tested population? The author believes that in order to convince westerners, if the communication strategy has no effect on the Chinese people themselves, it is also a kind of "self-deception" when talking about our culture "going out", let alone considering the influence of young people as a popular website user.

Results display and analysis. We used excel to compare the data collected between the two groups A and B. The data came from paper questionnaire: 0 points equaling to no understanding; 1 point, a little understanding; 2 points, basic understanding; 3 points, understanding well. And the calculated two group $\mathrm{P}$ value results retain three decimal places. In statistics, T-test is a method for inferring the probability of occurrence of differences. If the calculation result is that the $\mathrm{P}$ value is more than 0.05 , the null hypothesis is accepted; if the P value is less than 0.05 , the null hypothesis is rejected which indicates there is statistical significance difference in the two tested groups. 


\begin{tabular}{|c|c|c|c|c|c|}
\hline The adults in A group & The adults in B group & $P$ value & The teenagers in A group & The teenagers in B group & $P$ value \\
\hline 1 & 2 & & 1 & 1 & \\
\hline 0 & 1 & & 0 & 2 & \\
\hline 1 & 1 & & 1 & 1 & \\
\hline 2 & 1 & & 1 & 2 & \\
\hline 0 & 1 & & 2 & 2 & \\
\hline 0 & 2 & & 1 & 1 & \\
\hline 1 & 1 & & 1 & 2 & \\
\hline 2 & 1 & & 2 & 1 & \\
\hline 2 & 2 & & 1 & 1 & \\
\hline 0 & 2 & & 0 & 2 & \\
\hline 1 & 2 & & 0 & 2 & \\
\hline 1 & 1 & & 2 & 2 & \\
\hline 1 & 2 & & 1 & 1 & \\
\hline 1 & 2 & & 2 & 1 & \\
\hline 1 & 1 & 0.025 & 0 & 2 & 0.032 \\
\hline
\end{tabular}

We see the $\mathrm{P}$ values of the group $\mathrm{A}$ and $\mathrm{B}$ are both less than 0.05 , so it is rejected that there is no significant difference between direct reading of the Chinese painting compositions' definitions and direct reading the definitions with related Chinese painting illustrations.

\section{Illustration-Based Translation Method Exploration}

Editing original image. Benjamin March in his book Some Technical Terms of Chinese Painting mentioned “宾主 bīnzhǔ” (guest and host; the principle of balancing large mountains by small ones, a main flower by less important ones or by a butterfly) (1935, p. 25); Mai-mai Sze (1956) in his book The Way of Chinese Painting Its Ideas and Technique With Selections From the Seventeenth Century Mustard Seed Garden Manual of Painting mentioned “开合 kāihé" (open-together, pertaining to arrangement, balance, sequence, and rhythm in elements of a picture). Their translation methods for Chinese painting composition rules are literal translation and interpretation. Based on the results of significant differences, we propose one of the methods for illustration-based translation of Chinese painting composition rules: editing original image . Translators can choose the most understandable Chinese painting picture as the visual element of interpretation according to the type of text or the purpose of communication. We first look at a translation example ${ }^{1}$.

(1) 陈子庄的《峨嵋道上》采用了呼应式，右侧远山挺拔向上，与近景的山形成一种呼应关系。 (Chénzizhuāng de "éméi dàoshàng" căiyòngle hūyìng shì, yòu cè yuăn shān tǐngbá xiàngshàng, yǔ jìnjǐng de shānxíng chéngyī zhǒng hūyìng guānxì.)

Translation: In his painting, on the Way of Mountain Emei, Cheng Zizhuang adopted the principle of hu yin (call and response), an interaction relationship in Chinese traditional painting with others. We can see the far mountain in the right of the painting is tall and straight, interacting with the near one.

Starting from (1), we choose two original Chinese painting images as illustrations to show the specific visual manifestation. We can see the relationship more clear between flowers and flowers, between leaves and leaves, between flowers and leaves, and the relationship between the bird and the flower.

\footnotetext{
1 The original pictures of Chinese painting in (1), (2) and Example 3 are all from Baidu pictures http://image.baidu.com/.
} 


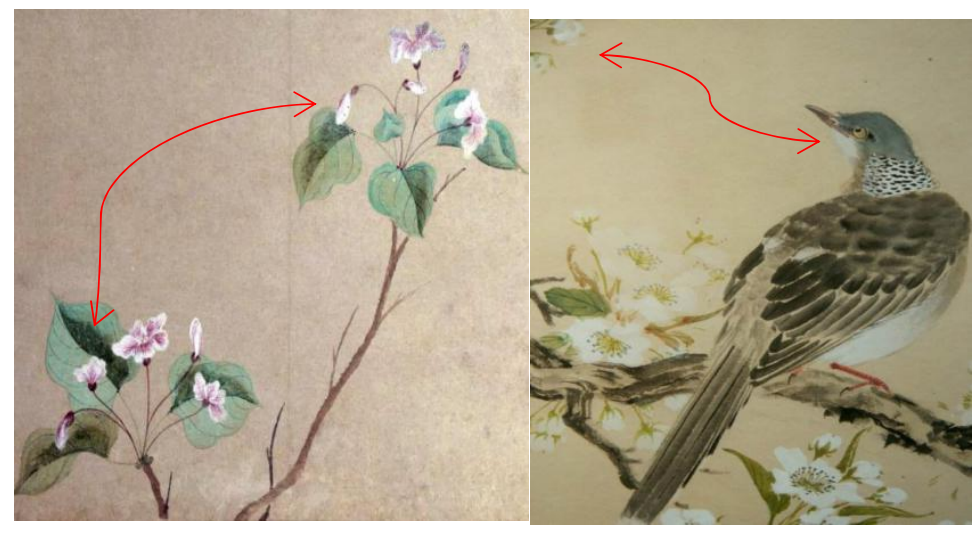

Simple drawing. In the analysis of the three stages of conquering the illusion of Chinese landscape painters, Wen C. Fong used Zhao Mengfu's 《鹊华秋色图》(Què huá qiūsè tú) as a blueprint to illustrate the landscape factor of a continuous retreat on the ground (Wen, 2003, p. 23), as shown below.

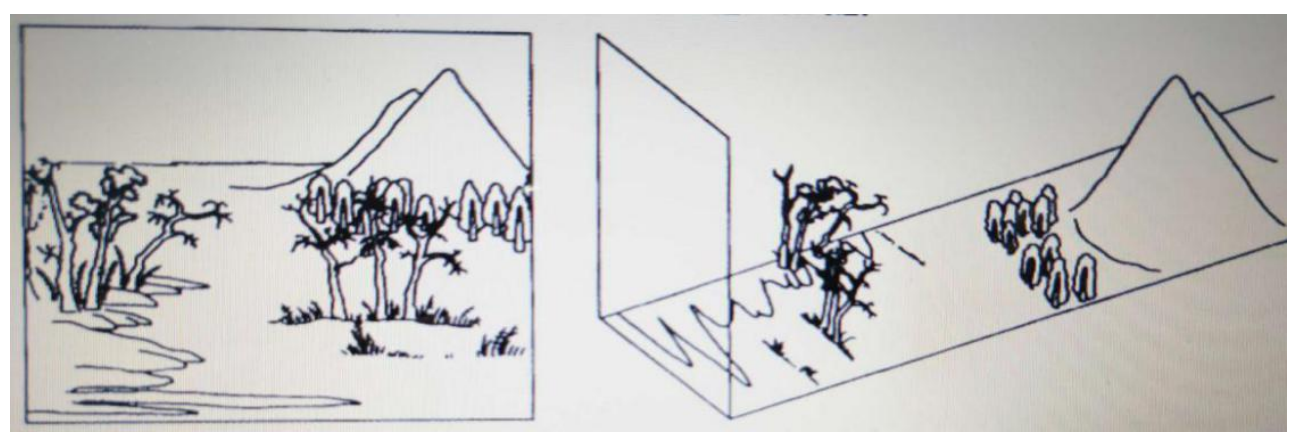

We can learn this representation method-using the simple drawing. The author want explaining the "gathering and distribution" through this method, see (2).

(2) 古人画树时有聚有散, 三株五株, 分反正阴阳, 参差高下, 生动有致。(Gǔrén huà shù shí yǒu jù yǒu sàn, sān zhū wǔ zhū, fên fănzhèng yīnyáng, cêncī gāo xià, shēngdòng yǒuzhì.)

Translation: The ancients painted trees in groups of either three or five. They let there be gathering, distribution, front views, back views, darkness and light (yin and yang), each having its own perfect form.
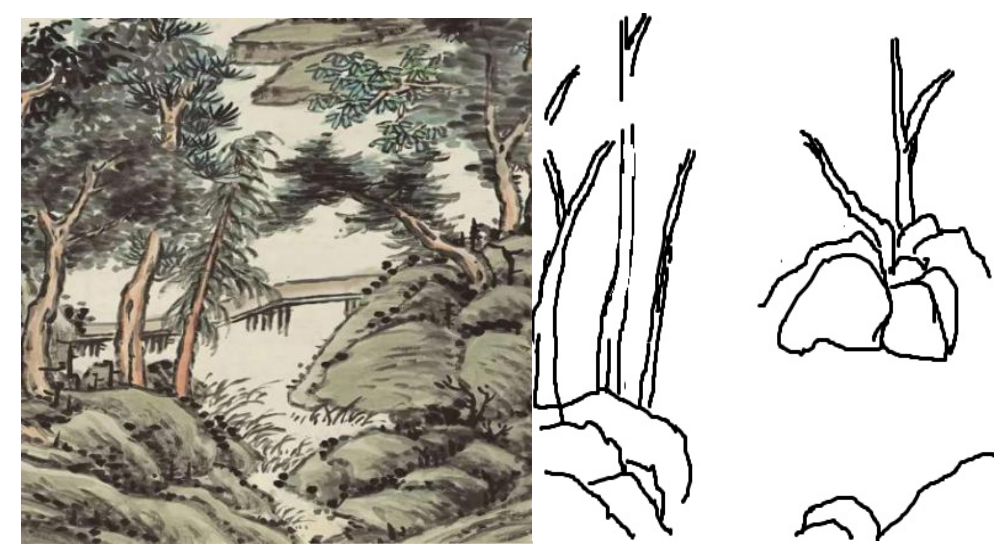

GIF (Graphics Interchange Format). From the study of Chinese painting or appreciation of experience, viewers must first go through the object image (outer vision) including the form of pen and ink, frame size, 
picture color, decoration pattern, etc., to imagery (internal vision), hence strengthening the appeal to the audience and laying the foundation of inner vision for the audiences to truly feel the uniqueness of the imagery of life in the universe of Chinese painting and calligraphy. Compared with the other illustrations, GIF is lively and can carry more key content. It is explaining the Chinese painting composition rules by either a picture or a small video. We used a Chinese painting composition rule “虚实 (xūshí) ${ }^{2}$ ” as an example to make the GIF picture, see Example 3. You can play it in full screen by double-clicking the picture, and press Esc to exit full-screen playback. Example 3 is showing the GIF made by selected landscape painting pictures; and the GIF can be also made by selected teaching small video of any Chinese ink painting categories.

Example 3

$$
\begin{aligned}
& \text { xu shi :empty and solid; the } \\
& \text { balancing of solidly drawn color, ink } \\
& \text { strokes,trees,mountians, and terrain } \\
& \text { by empty space }
\end{aligned}
$$

\section{Conclusion}

Due to the influence of various objective factors, it is also the shortcoming of this research, that is, it is inconvenient to use Flash animation, network video, or local video to explain the Chinese painting composition rules. We suggest that the translator should screen the corresponding Chinese painting pictures, make a simple drawing or dynamic picture according to the purpose of communication, and flexibly cope with the texts to provide visual clues for cross-cultural readers in order to better achieve the purpose of communication and consolidate the Chinese painting "going out". After all, introducing foreign cultural information in the context of fast food reading in today's society is not feasible for ordinary readers.

\section{References}

Bush, S. (2012). The Chinese literati on painting: Su Shi (1037-1101) to Dong Qi chang (1555-1636). Hong Kong: Hong Kong University Press.

Guo, Y. (2010). On the composition rules of Chinese painting. Art Theory, 9, 70.

Lu, C. X. (2008). Constructing in the heart and resolving the situation-Rethinking the theory of Chinese painting composition. Art Theory, 6, 10.

Mo, G. B. (2016). Taiji diagram and the traditional concept of Chinese painting composition. Guoxue, 5, 57.

March, B. (1935). Some technical terms of Chinese painting. Baltimore: Waverly Press, Inc.

Sze, M.-M. (1956). The way of Chinese painting its ideas and technique with selections from the seventeenth century mustard seed garden manual of painting. New York: Random House, Inc.

Wen C. Fong. (1992). Beyond representation Chinese painting and calligraphy 8th-14th century. New York: The Metropolitan Museum of Art.

Wen C. Fong. (2003). Heart print: Chinese painting and calligraphy style and structure analysis. (W. Z. Li, Trans.). Shaanxi: Shaanxi People's Publishing House.

${ }^{2}$ English translation of the word “虚实” in GIF from Benjamin March. Some technical terms of Chinese painting, p. 25. 